\title{
O PROFESSOR COMO SUJEITO DA APRENDIZAGEM E AS IMPLICAÇÕES DA ESCOLA DE VIGOTSKI*
}

\author{
Marly Teixeira Morettini** \\ Sônia da Cunha Urt ${ }^{* * *}$
}

\section{Resumo}

Este artigo, focaliza a aprendizagem do professor, compreendendo-a como um processo, que avança a partir da alteração das possibilidades de experiência e motivação para o sujeito do aprender. Entendendo-se que ele está sempre se transformando, nas relações sociais estabelecidas, o texto aborda a importância do significado das experiências realizadas para a sua constituição como sujeito. Nestas reflexões foram importantes as contribuições dos psicólogos soviéticos para a compreensão do homem como um sujeito histórico-concreto e para o entendimento do desenvolvimento do psiquismo humano, numa visão menos fragmentada, ao estabelecer que o ser humano constitui-se na dialética apropriação/objetivação dos bens da cultura e que as idéias teóricas por ele internalizadas, funcionam como mediadoras para o avanço dessa relação, que se efetua nas atividades.

Palavras- chave: Constituição do sujeito Aprendizagem Desenvolvimento do Professor

\section{THE TEACHER AS A LEARNIG SUBJECT AND THE IMPLICATIONS OF THE} VIGOTSKI THEORY

\begin{abstract}
This article focuses on the teachers' learning process, that develops through the change in experience possibilities as well as the motivation to learn. Considering that one is in perpetual transformation, in regard to established social connections, the test addresses the importance of the experiences'significance to the teachers'identity. The contribution of soviet psycologists was important to these reflections in understanding man as a concrete historic identity and the development of the humam psyche in a less fragmented vision, and on establishing that man is built on dialect appropriation/externalization of cultural

\footnotetext{
* Artigo recebido em 12/5/2008 e aprovado em 12/9/2008.

** Mestre em Educação, professora de Pedagogia da Universidade Federal de Mato Grosso do Sul (UFMS). Email: marlytm@terra.com.br

**** Doutora em Educação, professora de Psicologia da Universidade Federal de Mato Grosso do Sul (UFMS).
} 
property, and that internalized theoretical ideas act as mediators in the advance of these connections, apparent in the activities.

Key words: Identity Learning Process Developement Teacher

Algumas considerações

Utiliza-se, neste artigo, a expressão processo de constituição do sujeito por se acreditar que não existe um sujeito pronto e acabado e que ele está sempre se transformando no movimento das relações vivenciadas.

Entende-se que, no cotidiano, o professor vai construindo conhecimentos, concepções elaboradas nos diferentes espaços educativos, na educação formal, na atividade profissional, nos grupos de estudos, nas vivências do ensino, nas relações com os colegas, enfim, nas tantas relações sociais estabelecidas.

Em sua caminhada, ele apreende essas experiências que são sociais, reelaboraas individualmente e as devolve para a sociedade. É, nesse processo de internalização do significado das experiências, ele se constitui como sujeito.

Torna-se importante considerar as influências culturais às quais o sujeito se vê exposto, para poder apreender nesse cenário, como ele se percebe e como ocorrem as suas transformações nesse movimento. É intenção estudá- lo na atividade que exerce e na qual se constitui, por se acreditar que muitas das questões internalizadas estão relacionadas ao seu fazer; retomar as contribuições do pensamento da escola de Vigotsk,(1) para o melhor entendimento de um sujeito histórico; utilizar o entendimento das categorias atividade, consciência e identidade para o estudo do desenvolvimento do psiquismo humano.

A hipótese é a de que o sujeito da ação, nunca está pronto, nem terminado, ele vai se transformando sempre, conforme as suas experiências de vida, que lhe permitirão dar saltos qualitativos ou não, em seu processo de aprendizagem.

Para se tentar compreender o processo de constituição do sujeito, na visão da abordagem histórico- cultural da Psicologia, a partir das concepções por ela adotada, é importante entender que esse sujeito passa por um longo processo de aprendizagem e desenvolvimento, através do qual vai constituindo os aspectos que permitirão reconhecê-lo, na representação de seu fazer cotidiano.

Cada homem é único, tanto genética como culturalmente e vai se submeter a toda sorte de influências sociais. Será dependente, portanto, das oportunidades de Educação ao longo da vida e das experiências que realizar. A constituição desse sujeito no mundo é assim gerada por uma complexa rede de relações humanas - o que os homens construíram, todos os acontecimentos de que foram agentes, numa seqüência de experiências que se somam no decorrer de sua história, criando um processo ao qual o sujeito se vincula, no espaço social e no tempo histórico.(2)

Tanto a cultura como a subjetividade, são criações históricas e coletivas. A constituição do sujeito ocorre nos movimentos que ele consegue realizar em direção aos 
desafios do mundo e, nessa caminhada, envolvendo ações e relações, ocorrem momentos de identificação e diferenciação para a sua consciência. Por isso pretende-se:

1)estudar a constituição do professor, a partir das categorias atividade objetivada, consciência e identidade, entendendo-se que a hominização provém da vida em sociedade, no seio da cultura, criada pela humanidade; 2)retomar a relação aprendizagem/ desenvolvimento, nessa constituição, acreditando-se que, esses são dois processos distintos e interdependentes, cada um tornando o outro possível; 3)rever a aprendizagem do professor, considerado como um sujeito histórico, resgatando a importância da abordagem histórico-cultural da Psicologia para o entendimento das suas funções psicológicas superiores e a qualidade das experiências adquiridas para o seu processo de transformação; 4)retomar a concepção de conceitos, proposta por Vigotski, na relação aprendizagem/desenvolvimento do professor, entendendo-se que ele realiza o percurso proposto pelo autor, enquanto se constitui como profissional protagonista da prática docente.

\section{A constituição do sujeito e a relação aprendizagem/desenvolvimento}

A busca das colaborações de Vigotski e Leontiev, neste artigo, tem a intenção de encontrar algumas explicações que possam ajudar no estudo, procurando entender o sujeito como histórico e os processos subjetivos como um reflexo da realidade objetiva. Nesse sentido, o objetivo é romper com as idéias cristalizadas a respeito do desenvolvimento do psiquismo humano, na tentativa de estudar o processo de constituição do sujeito, em suas transformações. O trabalho realizado por ele aparece, então, como um elemento importante nesse processo de constituição.

O homem é diferente dos demais seres porque é capaz de criar, produzindo as suas condições de existência, enquanto vai dilatando as suas possibilidades de hominização.

A partir das leis biológicas, há o início, na formação do homem, de elementos novos em seu desenvolvimento. Começam a produzir-se, sob a influência do trabalho e da comunicação, através da linguagem que ele suscita, modificações na estrutura anatômica humana, no cérebro, nos órgãos dos sentidos, na mão, na linguagem, concluindo - o desenvolvimento do homem torna-se dependente do desenvolvimento da produção. "Assim se desenvolvia o homem, tornado sujeito do processo social do trabalho, sob a ação de duas espécies de leis: em primeiro lugar as leis biológicas, em virtude das quais seus órgãos se adaptaram às condições e às necessidades de produção; em segundo lugar às leis sóciohistóricas que regiam o desenvolvimento da própria produção e os processos que ela engendra. (LEONTIEV,1978 b, p.132).

O homem foi evoluindo, sob o processo social do trabalho - as condições históricas e o seu modo de vida sofreram, em ritmos sempre mais rápidos, modificações incríveis que foram sendo fixadas pela humanidade. Nesse sentido, ele foi se apropriando dos bens da cultura, participando do trabalho, da produção e das diversas formas de atividade social, formando assim, as aptidões especificamente humanas.

As gerações humanas sucedem-se, mas, a sua produção é passada para as gerações seguintes, que a aperfeiçoam pelo trabalho e a transmitem às outras que virão. 
Leontiev (1978b), apoiando-se em Marx, observa que o trabalho é uma atividade que distingue o ser social do ser natural, isto é, define a especificidade do ser humano como ser histórico, pelo fato do trabalho possuir certas características: a de ser uma atividade consciente dirigida por uma finalidade previamente estabelecida na consciência e a de ser uma atividade que se materializa em um produto social, um produto que não é mais um objeto inteiramente natural, um produto que é uma objetivação da atividade e do pensamento do ser humano.

As aquisições históricas resultam então, do desenvolvimento das gerações humanas, não são incorporadas no homem, nem em suas disposições naturais, mas nas grandes obras da cultura humana. O homem apropria-se delas no decurso de sua vida. Mas, nem sempre essas apropriações encontram condições sociais favoráveis. Na sociedade de classes, por exemplo, a aquisição encontra limitações pelo caráter restrito da própria atividade e a apropriação pode acontecer em condições precárias.

O nascimento físico não é o suficiente para o ingresso na história. E é, por essa localização social, que se define o conteúdo da ligação do homem à cultura. A cultura, nessa perspectiva, é um processo de acumulação de experiências que o homem realiza, vai aprendendo a diferenciá-las, a guardar os seus significados, a transformá-las em idéias, num primeiro momento muito próximas à realidade e depois generalizadas a partir do contato com o mundo.

A constituição do sujeito é, portanto, sempre um processo educativo, mesmo quando essa educação realiza-se de maneira informal, sem uma relação consciente, tanto da parte de quem aprende, como da parte de quem faz a mediação e o espaço educativo está existindo, no interior dessa prática social. Porém, a contradição nessa constituição, acontece nas mais diversas combinações para se configurar uma totalidade e, a relação entre o sujeito, o contexto onde vive, as práticas e ações realizadas por ele, colocam o seu estudo diante de uma situação que exige muitas discussões teóricas.

Para assumir essas discussões, foi preciso que, os psicólogos soviéticos, liderados por Vigotski, sistematizassem uma abordagem para o melhor entendimento das funções cognitivas complexas de um sujeito contextualizado e, portanto, histórico e para isso, buscaram subsídios no materialismo histórico, método que estuda os fenômenos em movimento e em mudança. Na concepção vigotskiana, coerente com esses pressupostos, organismo e meio determinam-se mutuamente, portanto o biológico e o social não estão dissociados, pois, exercem influência recíproca. Nessa perspectiva, a premissa é de que o homem constitui-se como tal, através de suas interações sociais.

O desenvolvimento da estrutura humana é entendido assim, como um processo de apropriação pelo sujeito da experiência histórico-cultural. Nesse processo, o sujeito, ao mesmo tempo que internaliza as formas culturais, transforma-as e intervém em seu meio. Desse ponto de vista, o homem é visto como alguém que transforma e é transformado, nas relações produzidas em sua cultura. É portanto, na relação dialética com o mundo, que o sujeito se constitui e se desenvolve. O ser humano não só é um produto de seu contexto social, mas também um agente ativo na criação desse contexto. "Para se apropriar dos objetos ou dos fenômenos que são o produto do desenvolvimento histórico, é necessário desenvolver em relação a eles uma atividade que reproduza, pela sua forma, os traços essenciais da atividade acumulada no objeto”. ( LEONTIEV,1978 p. 250). 
É necessário ressaltar que, nessa abordagem, o que ocorre não é uma somatória, nem tão pouco uma justaposição entre os fatores inatos e os adquiridos, e sim uma interação dialética que se dá, desde o nascimento, entre o ser humano e o meio cultural em que se insere. Para Vigotski (1988) a estrutura fisiológica humana, aquilo que é inato, não é suficiente para produzir o humano, na ausência do ambiente social. As características individuais (modo de agir, de pensar, de sentir, valores, conhecimentos, visão de mundo) dependem da relação do ser humano com o meio físico e social e especialmente das trocas estabelecidas com os seus semelhantes, sobretudo dos mais experientes de seu grupo cultural.

Ao estudar o processo de constituição do sujeito, é importante rever as atividades que ele realiza, no movimento do processo de sua constituição, em desenvolvimento nas múltiplas inter-relações. "Pela sua atividade os homens não fazem senão adaptar-se à natureza. Eles modificam-na em função das suas necessidades. Criam os objetos que devem satisfazer as suas necessidades e igualmente os meios de produção destes objetos, dos instrumentos às máquinas mais complexas. Constróem habitações, produzem as suas roupas e outros bens materiais. Os progressos realizados na produção de bens materiais são acompanhados pelo desenvolvimento da cultura dos homens; o seu conhecimento do mundo circundante e deles mesmos enriquece-se, desenvolve-se a ciência e a arte." (LEONTIEV, 1978 a, p.265).

Se o sujeito constitui-se no transcurso de sua vida, através da apropriação da cultura historicamente acumulada, esse processo acontece numa gradual interiorização do externo, social e a sua transformação em interno, individual. Produz-se na comunicação e nas relações sociais que ele estabelece nos diferentes grupos em que participa, na atividade que realiza, de acordo com as suas condições objetivas de vida. Essa reflexão dá para o processo de constituição do sujeito um caráter de mobilidade - é um processo em movimento - que está sempre se (re) fazendo e, ao sujeito um papel ativo em sua própria constituição, pois embora se constitua nas relações sociais ele interioriza as significações a partir de uma elaboração que é pessoal.

A consciência humana, outra categoria estudada por Leontiev (1978b), para explicar o desenvolvimento da constituição do sujeito, possui um conteúdo psicológico que, segundo o autor, só poderá ser revelado a partir das relações que o ser humano estabelece com o mundo. Nessa perspectiva, as transformações ocorridas em sua estrutura também poderão ser observadas na atividade que ele realiza e onde alarga as suas relações. Leontiev observa que a consciência é uma etapa superior nesse desenvolvimento porque dá ao homem a capacidade de distinguir entre o objeto e as impressões que se tem dele. Para que o homem se encarregue de sua atividade é preciso que descubra o seu significado, que tenha consciência dele.

A atividade humana estabelece dessa forma, uma ligação entre o objeto da ação (fim) e o gerador da atividade (motivo). Reflete-se na cabeça do homem, como numa relação prático/objetiva do sujeito/objeto. Nesse sentido, a consciência passa a fazer a distinção entre a atividade e o objeto. $\mathrm{O}$ objeto passa a se distinguir não só de maneira prática, mas teoricamente, tornando-se uma "idéia". "O homem pode pensar uma ação, direcioná-la para um fim, torná-la atividade e internalizá-la novamente. Nesse sentido, a 
consciência opera concretamente na realidade circundante, através da linguagem. A consciência é inseparável da linguagem. "Como a consciência humana, a linguagem só aparece no processo de trabalho, ao mesmo tempo que ele”. (LEONTIEV, 1978b p. 85)

É importante que se diga que é esse desenvolvimento que implica na constituição da identidade como um processo de transformações qualitativas. Nesse sentido, esse desenvolvimento envolve outros níveis de consciência para que não haja simplesmente simulação, transformação ilusória, resposta às expectativas determinadas pelas condições sociais.

Para Ciampa (1994, p. 157) identidade é transformação, é articulação de várias personagens, articulação de igualdades e diferenças, constituindo e sendo constituída por uma história pessoal; identidade é metamorfose. "Identidade é história. Isto nos permite afirmar que não há personagens fora da história, assim como não há história (ao menos história humana) sem personagens".

O que é importante, principalmente entender, é que a identidade é constituída no movimento, não é pronta nem acabada, mas é contraditória e está sempre em processo de transformação. Atividade, consciência e identidade são, pois, as unidades de análise utilizadas, neste artigo, para explicar a constituição do sujeito histórico.

Estudar essa constituição, considerando a relação aprendizagem/ desenvolvimento, implica em se considerar a atividade que ele executa, por se entender que na atividade, o psiquismo humano se desenvolve e estabelecem-se muitas das relações que levarão às transformações da estrutura desse mesmo psiquismo, embora se compreenda que o sujeito não assimila rapidamente a experiência histórico-social com a qual entra em contato em suas relações sociais. Ele passa por um longo processo de aprendizagem e desenvolvimento, através do qual vai constituindo os aspectos que permitirão reconhecê-lo como sujeito.

Rever "o fazer" significa rever o sujeito em suas relações sociais, tanto na especificidade da tarefa que ele realiza como nas manifestações reveladas pelo grupo ao qual pertence e pela sociedade como um todo. Recuperar a atividade como constituinte do sujeito é importante porque ela é o processo mediante o qual o indivíduo, ao responder às suas necessidades, relaciona-se com a realidade, ao mesmo tempo em que adota posições e atitudes diante dela, fato que poderia implicar numa análise menos fragmentada do sujeito.

$\mathrm{O}$ ato humano é consciente da finalidade, isto é, o ato existe antes como pensamento, como uma possibilidade e a execução é o resultado da escolha dos meios necessários para atingir os fins propostos. E, caso haja interferências externas no processo, os planos também serão modificados. O trabalho humano é a ação dirigida por finalidades conscientes, a resposta aos desafios da natureza na luta pela sobrevivência. Ao reproduzir técnicas que outros homens já usaram e ao inventar outras novas, a ação humana torna- se fonte de idéias e, ao mesmo tempo uma experiência propriamente dita

A relação desenvolvimento/ aprendizagem, que implica na constituição do sujeito, pode ser explicada em várias teorias, cujos estudiosos apresentam idéias contrárias, trazendo uma série de controvérsias sobre o tema que os colocam em lugares opostos. Mas, cada uma delas descobriu uma variedade de conceitos que fazem com que o conhecimento avance no entendimento da questão.

Vigotski rejeitou todas as abordagens existentes em sua época, reconhecendo que Aprendizagem e Desenvolvimento são dois processos distintos e interdependentes, cada um 
tornando o outro possível. Uma das grandes contribuições de seus estudos para a Psicologia, foi compreender e não apenas pressupor, processos, através dos quais, o desenvolvimento é socialmente constituído.

Diante das críticas feitas à abordagem centrada apenas no sujeito, sem levar em conta as relações sociais, que reduz o pedagógico ao psicológico, uma saída seria encontrar respostas para as questões que incorporassem o sujeito histórico. E esse foi o pensamento da escola de Vigotski. Ao pretender sistematizar uma abordagem fundamentalmente nova sobre o processo de desenvolvimento do pensamento, uma abordagem que desse conta de explicar as funções cognitivas complexas de um sujeito contextualizado e, portanto histórico, Vigotski empreendeu um estudo aprofundado das concepções teóricometodológicas com as quais a Psicologia contava até então, para explicar os processos humanos. Sua observação foi a de que, boa parte dos métodos disponíveis apoiavam-se no que ele chamou de "estrutura estímulo-resposta". Para o autor, esses métodos permitiam apenas identificar as variações quantitativas na complexidade dos estímulos e nas respostas fornecidas por diferentes sujeitos.

Vigotski ficou profundamente preocupado com uma nova forma de pesquisar que considerava a influência do social no processo de desenvolvimento das funções psíquicas do homem e, para tentar compreender como acontece o processo de aprendizagem e desenvolvimento do sujeito, no movimento das relações vivenciadas, foi importante para ele e seus companheiros, uma outra visão de homem e de mundo.

Uma contribuição muito importante dos estudos de Vigotski às questões pedagógicas, consiste na concepção de que as funções psíquicas do professor são constituídas à medida que são solicitadas, na dependência do legado cultural da humanidade. Nesse sentido, esse desenvolvimento é entendido como vinculado à apropriação da cultura humana, dentro da sociedade na qual ela está inserida. Vigotski tentou compreender os processos, através dos quais o desenvolvimento humano é socialmente constituído, e foi para explicar essa questão que ele elaborou conceitos importantes dentro da teoria.

Discutindo os mecanismos pelos quais, na relação com o outro, as experiências de aprendizagem criam o desenvolvimento, recorreu aos conceitos de Zona de Desenvolvimento Proximal e de Internalização. Para o autor, o importante não era chamar a atenção para o social, mas superar o modelo ahistórico da Psicologia na explicação do homem contextualizado. Isso significa que o homem, ao produzir as condições de sua existência, ao transformar a natureza, se apropria e se objetiva nela. Essa apropriação e essa objetivação geram nele novas necessidades e conduzem a novas formas de ação. Cada indivíduo nasce situado espacial e temporalmente nesse processo e, para dele participar, isto é, para se objetivar no interior dele, precisa apropriar- se das objetivações (entendidas como os produtos da atividade objetivadora humana) - resultados do processo histórico.

Vigotski chama a atenção para a importância que o conteúdo da aprendizagem tem ao exigir do sujeito a utilização de capacidades que ele ainda não tem, mas que estão sendo formadas. Se a aprendizagem não apresentar maiores exigências para o sujeito, ele se limitará ao nível de desenvolvimento existente. É nesse sentido que aprendizagem exerce a sua função na relação com o desenvolvimento.

Pode-se afirmar, portanto, que o conceito de Zona de Desenvolvimento Proximal (ZDP), na teoria vigotskiana (conceito que revela a diferença entre o nível das tarefas 
realizadas com o auxílio de um terceiro elemento e o nível das tarefas que o sujeito pode desenvolver sozinho, independentemente de ajuda) retoma a questão da importância do processo de aprendizagem, realizado na mediação, como investimento no desenvolvimento intelectual e na apropriação de conhecimentos. Segundo o autor, ZDP é “A distância entre o nível de desenvolvimento real, que se costuma determinar através da solução independente de problemas e o nível de desenvolvimento potencial, determinado através da solução de problemas sob a orientação de um adulto ou em colaboração com companheiros mais capazes (VIGOTSKI 1988, p.112).

Mas, a apropriação só se dará de forma qualitativa se for realizada em condições adequadas, o que não significa aumento das informações repassadas e sim desenvolvimento da capacidade de aprender a separar o objeto do seu significado. Com esse conceito e com o de Internalização, que consiste no movimento do sujeito em interiorizar o significado de suas experiências, Vigotski mostrou que o caráter social da atividade do sujeito não está meramente na existência de um contexto social que gera os processos subjetivos . A dimensão intersubjetiva está na gênese da atividade individual.

Na perspectiva vigotskiana, a aprendizagem inicia-se muito antes da entrada na escola. Aprendizagem e desenvolvimento estão relacionados desde o primeiro dia de vida do sujeito e a aprendizagem escolar nunca parte do zero, pois antes de ir para a escola o sujeito já viveu uma série de experiências importantes. À medida que o autor viu a aprendizagem como um processo essencialmente social (ocorrido na interação com adultos e companheiros mais experientes, mediado pela linguagem), percebe-se que as funções psicológicas superiores são construídas na cultura, pela apropriação dos conhecimentos historicamente acumulados e a Educação pode, nesse sentido, abrir novas perspectivas para a redefinição do papel da escola e do trabalho pedagógico.

\section{O professor como sujeito da aprendizagem}

Em cada momento da vida surgem novas experiências, que se objetivam em maneiras diferentes de ver, sentir, entender e agir no mundo, criando seus diferentes sentidos, a partir das condições de cada época, em espaços e períodos expressivos da sociedade em que se vive e do cenário social e histórico que a produz.

A revolução técnico-científica, principalmente a informática, vem provocando modificações profundas no modo de se sentir o mundo, estabelecendo novas formas de ressignificar o real.

Ferreira (1996) falando sobre o desafio de viver no mundo de hoje, observa que o consumo, como palavra de ordem, pode direcionar o olhar mas cega na medida em que impede que se veja outras coisas que não aquilo que está sendo exibido como único. De todos os lugares chegam informações que elaboram padrões de conduta e de valores. Se o homem vai sobreviver tranqüilo a tudo isso, não se sabe, nem é possível deixar de reconhecer que a rede de imagens é um excelente veículo de socialização de informações.

Rey (2003) observa que a subjetividade social e individual atuam na qualidade de constituintes e constituídos do outro e pelo outro. Esta colocação conduz a uma representação de sujeito em que a condição e o momento atual de sua ação, expressam 
sentidos subjetivos oriundos de diferentes espaços de suas experiências sociais. Dessa maneira, o sujeito que aprende expressa a subjetividade social dos diferentes espaços sociais em que vive no processo de aprender e nenhuma atividade resulta em uma atividade isolada do conjunto de sentidos que caracterizam o mundo histórico e social da pessoa.

Essa discussão é muito importante para a Educação, uma vez que nas salas de aulas geram-se sentidos e significados inseparáveis das histórias das pessoas envolvidas, assim como da subjetividade social da escola, na qual aparecem elementos de outros espaços da subjetividade social.

A escola, está inserida na sociedade da qual faz parte e com a qual vive em constante relação. $\mathrm{O}$ espaço educativo é um espaço de convergência, divergência e contradição social, no qual entram em jogo inúmeros sentidos e significações, presentes em outras formas de vida social. Entre os caminhos para a compreensão da escola e da permeabilidade que a cultura oferece aos processos educacionais, socialmente realizados, há proposições que se aproximam - considerar as condições sociais específicas e históricas é uma delas.

A questão da constituição desse sujeito da aprendizagem que está sendo discutida, aceita a idéia de que a sua origem e constituição é de natureza histórico social. Destaca-se pois, a partir dessa postura, o papel do outro, a mediação simbólica, a apropriação dos significados culturais e o desenvolvimento dos conceitos. Essa constituição portanto, nunca está dada e, como já disse Rey (2003) a respeito do sujeito, o professor se constitui de diversas formas, em cada momento de sua vida, dependendo das forças e dos elementos que se colocam em jogo.

Sabe-se que a aprendizagem do professor não se dá entre as quatro paredes da sala de aula, ou somente nos bancos da Universidade; existe a necessidade de um investimento constante para melhorar a sua qualidade. Não se pode mais acreditar na idéia de uma formação acabada, um produto pronto e, a Universidade, a Escola e a própria Sociedade têm que compreender esse fato. Entende-se a importância da formação inicial na docência, mas sabe-se que Cursos, Reciclagens, Treinamentos ou outros nomes quaisquer que se queira dar a esses tipos de "aperfeiçoamentos", não têm resolvido a questão de uma prática mais efetiva por parte do professor. Nesse sentido, existe a necessidade de uma alternativa que facilite a tomada de consciência por parte dos professores, em relação à prática pedagógica, independentemente do lugar e do momento em que se realiza o desenvolvimento profissional.

Fica muito difícil para o professor, em sua prática cotidiana, retomar as teorias estudadas em sua vivência acadêmica, e a situação torna-se complicada, causando momentos de incertezas e conflitos, no desempenho das atividades docentes. As teorias que vêem a escola como aquela que deve se adaptar às mudanças externas, deixam o professor numa situação bastante desconfortável, para poder continuar a cumprir o seu papel pois, ora ele é reverenciado como um sacerdote, ora execrado como um conservador, ora ridicularizado pela sua impotência, ora um revolucionário castrado, como afirma Petitat (1994). Essas imagens reduzem o seu papel de ator e reduz a instituição a um mero instrumento.

A constituição do educador como protagonista de sua prática é um processo construído lentamente e, a teoria vista na academia pode, muitas vezes, não ser útil, da forma como é estudada. Necessário se faz então, uma outra visão da teoria, na medida em 
que o professor vai se apossando lentamente dela. Oferecer a teoria aos professores que estiverem em busca de novas referências para o repensar de seu trabalho.

Para sanar essas angústias é que o professor tem procurado, ao longo do tempo, recorrer à Psicologia na esperança de tentar resolver os seus conflitos, a partir da apropriação de seus conceitos. E, é aí que essa área se insere como campo de conhecimento importante.

As experiências com diferentes profissionais envolvidos no processo educativo vêm confirmar a necessidade de articulação nas várias áreas de conhecimento, afim de que se tenha uma visão mais ampla do processo de aprendizagem do professor, para que se possa intervir nele.

Nessa perspectiva, Alvite (1981), fez uma análise crítica, com muita consistência, acerca das relações entre a Educação e a Psicologia evidenciando o "psicologismo" na Educação. Esse trabalho, produzido no início da década de 80, representa uma referência necessária em qualquer análise que envolva discussões sobre a relação Psicologia e Educação e Psicologia e Didática. Seu interesse estava em perceber criticamente o tipo de influência exercida pela Psicologia no trabalho educativo e, conseqüentemente, suas implicações para a Educação.

Excede a finalidade deste trabalho resgatar as especificidades dos aspectos da tão discutida relação da Psicologia e Educação. O que procede é registrar que muitos outros pesquisadores, além de Alvite, estudaram o fenômeno do reducionismo dos problemas educacionais aos aspectos psicológicos, fato que passou a ser objeto de muitas críticas PATTO (1984); FERREIRA (1986); URT (1989); FREITAS (1992); MIRANDA(1999).(3)

É bem verdade que a Psicologia vem sendo criticada pelo enfoque clínico com que trata as questões da Educação, sem grandes experiências de aplicação na escola ou enfatizando muito o desempenho do aluno, os fracassos, ou seja, os problemas individuais. A função que se espera do psicólogo é daquele que está sempre buscando formas de intervenção na prática educativa e tentando diferentes maneiras de melhorar o desempenho do professor, mas as críticas continuam sendo feitas, em função do aspecto psicologizante dessa intervenção.

Entretanto, os seus estudos, sem sombra de dúvida, têm sido muito importantes no sentido de enriquecer os olhares para o processo de Aprendizagem/desenvolvimento, de ajudar o professor a entendê-lo melhor e tentar interferir em suas questões.

Estudar os insucessos, tentar visualizá-los à luz dos grandes teóricos e explicitá-los aos professores é uma colaboração importante.

Nesse sentido, espera-se que o professor tente enxergar o seu processo de aprendizagem a partir das condições sociais. O que se necessita atualmente, é de uma melhor relação Psicologia/ Pedagogia, em termos de institucionalizar os conhecimentos que a primeira tem a oferecer ao processo educacional.

Ver o professor como um sujeito histórico e a Educação como prática social, ao mesmo tempo em que se enriquece o processo de desenvolvimento com as explicações que os conhecimentos psicológicos têm a dar.

Estudiosos do assunto, nos trabalhos apresentados nos encontros da ANPED (Associação Nacional de Pós-Graduação em Educação), nos últimos três anos, vêm pontuando a questão da importância do processo de aprendizagem do professor e o perigo 
que representa para a Educação a questão de profissionais mal formados, além de salientar o caráter de prevenção, tão importante para o processo educacional e a pouca atenção dada pela Escola, ao aspecto afetivo-emocional, em relação aos profissionais envolvidos e não só à criança. Além disso, os estudos psicológicos têm a oferecer para a escola, o exercício de lidar com grupos, pessoas e com o próprio conhecimento.

Através das incursões da Psicologia à escola, é que se tem aprendido a valorizar a formação de grupos de estudo entre os professores, estratégia importantíssima, em seu processo de desenvolvimento/aprendizagem.

Sacristán (1991) afirma que, as profissões definem-se pelas suas práticas e por um certo monopólio das regras e dos conhecimentos da atividade que realizam. Observa que os professores não produzem os conhecimentos que são chamados a reproduzir, nem determinam as estratégicas práticas de ação. Nessa perspectiva, é que se torna muito importante analisar o significado da prática educativa e compreender as suas conseqüências no plano da formação dos professores e da profissão docente, pois a atividade do professor não se circunscreve ao processo de ensino e de aprendizagem, principalmente à ação didática, tornando-se necessário sondar outras dimensões menos evidentes.

Na sociedade capitalista, com o surgimento da propriedade privada, o trabalho deixa de ter "valor de uso" e passa a ter "valor de troca", sob o controle de quem domina os meios de produção. O diálogo homem/natureza/outros homens, passa a ser mediado por aquele que compra a força de trabalho.

Aparece o trabalho sob os dois níveis de alienação - o "valor de uso" é substituído pelo "valor de troca" e o produto não pertence ao trabalhador - quem produz não tem acesso ao que produziu e esse processo de alienação pode acontecer tanto na esfera econômica, como na esfera intelectual. Na sociedade capitalista contemporânea, o sujeito é levado a consumir, tanto quanto os outros sujeitos, obedecendo a certa ordem dada que acaba impondo padrões de comportamento e o professor tem que sofrer o empobrecimento de suas experiências.

O que se quer observar, é que o processo de apropriação feito pelo homem, pode acontecer de forma qualitativa ou não, porque as suas apropriações são realizadas a partir da atividade que se dá, nas condições objetivas de vida. Então o seu processo de apropriação de conhecimento pode envolver "saltos qualitativos", como pode também cristalizar-se nos limites impostos socialmente.

Fica evidente que os docentes nunca abandonam essa idéia de transformar a sociedade e Imbernón (2000) vai referendar que o professor não pode ser apenas espectador passivo desse futuro, mas está reservado para ele um papel de sujeito-ator. Diante das opressões sociais e econômicas em que se encontra o homem na sociedade contemporânea, as condições acabam ficando difíceis para que ele cumpra essa função.

Duarte (2001) relembra que o primeiro aspecto do processo de esvaziamento do sujeito na sociedade capitalista é a redução do sujeito a alguém que produz "valor de troca”, que possui uma atividade traduzida numa quantidade e relaciona-se com a sociedade pela mediação do dinheiro, o instrumento universal do capitalismo para se medir o valor das atividades do homem e de seus produtos, é o ideário neoliberal que falseia tanto a crise do capitalismo, como a sua solução.

É interessante observar como os neoliberais entendem essa crise que afeta a Educação...Sabe-se que a democratização do ensino não se fez garantindo o nível de 
qualidade - não faltam só escolas, professores, verbas; faltam melhores escolas, melhores professores, melhores verbas... A ingerência do Estado, na política neoliberal, é um planejamento ineficaz com formas clientelistas e o modelo de intervenção estatal pode ser o grande culpado pela crise. A política econômica interfere na política educacional - O professor, o aluno e a escola são reféns dessa crise.

Na sociedade contemporânea, o Capital assume formas cada vez mais sofisticadas de estratégias, nas relações de produção, interferindo nos espaços sociais e institucionais, agindo em forma de elemento simbólico em todos os tipos de relações.

Entende-se que a constituição do sujeito é sempre um processo educativo, mesmo quando acontece de maneira informal, sem a relação consciente, tanto por parte de quem aprende, como de quem faz a mediação no processo.

O processo educativo do sujeito então, pode acontecer de uma maneira tal, que possibilite a realização de complexas e diversificadas tarefas dirigidas por fins conscientes, mas serem ao mesmo tempo alienadas e alienantes, na medida em que não fazem do sujeito um ser autônomo, isto é, ele pode ser um ser social, mas a sua socialização se reduz à identificação com as relações sociais de dominação. Ele pode ser um sujeito que trabalha e está inserido num contexto, mas não faz de si mesmo um homem livre.

A relação entre a apropriação dos bens da cultura e a sua objetivação realiza-se, portanto, sempre em condições determinadas pela atividade passada de outros seres humanos. Cada sujeito não pode se objetivar sem a apropriação das objetivações existentes. É, dessa forma, que ele realiza o seu processo constituição.

É certo que os problemas oriundos de condições sociais adversas fazem a mediação na constituição do sujeito, e, nesse sentido com as condições ruins de trabalho e com as violências sociais a que se vê submetido o ser humano, na sociedade capitalista contemporânea, o professor pode não se desenvolver plenamente.

Entende-se pois que a questão não é se o professor tem ou não aptidão para tornarse "sujeito protagonista" de sua prática, mas está na superação das condições que o permitam vir a interrogá-la.

A concepção de aprendizagem em que se acredita, é uma relação dinâmica, de apropriação de conhecimentos acumulados. Por se entender a aquisição do conhecimento como a apropriação do significado social das objetivações que se dão na atividade, é que se acredita que tanto o professor como o aluno (sujeitos da aprendizagem) se apropriam, através do mesmo processo, dos resultados das experiências vivenciadas. Nesse sentido, é que se buscou analisar, na teoria de Vigotski, as concepções de sua escola de pensamento, que pudessem ajudar a explicar os sujeitos envolvidos no processo de aprendizagem/desenvolvimento.

A partir do entendimento de Vigotski (1988), o professor precisa romper com os conceitos fossilizados para que possa entender e rever sua prática docente, seu fazer cotidiano, seus conceitos a respeito dos fundamentos teóricos para só então tomar decisões que resultem em uma aprendizagem significativa e mais efetiva.

As interpretações que vêm sendo realizadas pelos intelectuais brasileiros a respeito da Psicologia histórico/cultural e principalmente sobre Vigotski, o autor mais citado nos trabalhos que ostentam essa abordagem, têm recebido severas críticas pelo aspecto simplista com que reduzem o pensamento do autor e pelo caráter não científico das análises apresentadas. A crítica incide sobre pontos fragmentados, conceitos isolados retirados dos 
trabalhos sobre Vigotski, produzidos por diferentes autores e que referendam a prática docente, sem o devido aprofundamento teórico (não se trata de introduzir termos vigotskianos no vocabulário dos professores). Em conseqüência disso, acaba-se simplificando a contribuição da teoria à complementação de lacunas presentes em outras teorias.

Nesse processo, o educador acaba criando uma teoria pedagógica como resultante, alternativa, muito mais prática, cujos pressupostos teóricos podem não corresponder exatamente ao conhecimento historicamente acumulado e que precisam ser considerados, analisados, refletidos para que possam voltar-se às transformações que se pretende na prática educativa.

O pensamento pedagógico contemporâneo, não pode deixar de se preocupar com a superficialidade dos discursos que permeiam a escola, em que o pensamento e a cultura não aparecem. É Forquin (1993), que vai discutir essa idéia, afirmando que elucidar a questão dos fundamentos e das implicações culturais da educação é hoje, sem dúvida, uma questão difícil, porque é fragmentada, mas vale a pena ser perseguida, pois é a justificativa fundamental do empreendimento educativo que está em jogo.

Voltando ao pressuposto de que o ser humano constitui-se na dialética entre a apropriação/objetivação e que as idéias difundidas funcionam como mediadoras nessa relação que se dá entre pessoas concretas, na atividade realizada, é que cabe pontuar o cuidado que se deve ter com a forma como a Educação entende as teorias presentes no discurso difundido, e a apropriação feita pelos educadores desse mesmo discurso.

A historicidade do ser humano que Vigotski se propôs a afirmar, enfrentando a dicotomia presente no mundo das idéias, é o traço que caracteriza e diferencia a abordagem histórico-cultural, do pensamento das outras escolas da Psicologia.

Considerando todas essas reflexões é que se aceitou a idéia proposta, de formar um grupo de estudos com os professores - todos do Ensino Fundamental e, ao mesmo tempo, acadêmicos das $3^{\mathrm{a}}$ e $4^{\mathrm{a}}$ séries do curso de Pedagogia, da UFMS (4), interessados em ir mais a fundo nas questões teóricas, julgadas importantes para a sua atuação em sala de aula. Este estudo foi realizado, durante um ano, no período de duas horas por semana. O interesse com esse trabalho estava em investigar de que forma o professor está pensando as questões educacionais, o que está utilizando em sua atividade docente, que importância atribui à teoria e de que maneira está fazendo as articulações com essa teoria em sua atividade.

Em síntese, objetivava-se analisar as apropriações feitas pelos professores, das concepções da escola de Vigotski, teoria que os professores queriam estudar, através de estratégias escolhidas, dando ênfase ao rompimento com os conceitos fossilizados e à qualidade de sua prática no âmbito da escola.

A experiência, em si mesma, não é importante para este estudo, somente as análises sobre a aprendizagem dos professores, nas observações e conclusões retiradas é que se tornaram relevantes e permeiam as observações e as crenças colocadas neste artigo.

\section{O desenvolvimento de conceitos e o sujeito da aprendizagem}


A proposição de Vigotski, a respeito do desenvolvimento dos conceitos, remete ao estudo de sua teoria, mais especificamente à relação pensamento/linguagem, à mediação cultural na apropriação de significados pelo sujeito e ao papel da educação sistematizada na aquisição de conhecimentos de natureza diferente daqueles aprendidos na vida cotidiana.

Os conceitos, nessa abordagem, são construções culturais, internalizadas pelo sujeito, ao longo do seu processo de desenvolvimento. Vigotski (2001), propôs um percurso conceitual, ao tratar da forma como o sujeito evolui nesse processo, transformando os conceitos espontâneos em científicos.(5) $\mathrm{O}$ aparato biológico, tanto do aluno, como do professor, pode encontrar limites e possibilidades ao interagir com o mundo e com as formas culturalmente dadas que serão internalizadas e transformadas no material simbólico, mediador entre o sujeito e o conhecimento, no processo de desenvolvimento.

É, a partir dessas explicações que Vigotski (2003), retoma a importância da educação escolarizada (ou sistematizada), cujo papel seria o de transformar conceitos "espontâneos", ou aqueles adquiridos, informalmente, na vida cotidiana (em confronto com uma situação concreta) em conceitos “científicos”, adquiridos por meio de "ensino", como parte de um sistema organizado de conhecimentos, particularmente relevantes para a sociedade letrada, e que envolvem uma atitude mediada simbolicamente.

Uma criança encontra-se, desde que nasce, imersa no fluxo de comunicação das pessoas que a rodeiam e sem se dar conta da complexidade desse processo, vai aprendendo a fazer uso da linguagem e pode dizer uma palavra sem ter a exata idéia do que aquilo significa, em forma de pensamento abstrato; um adulto também pode ficar em nível de conceitos adquiridos espontaneamente, que se referem a representações do objeto e não ao próprio objeto de conhecimento.

Muitas vezes, o professor trabalha com base em seus conceitos espontâneos, gerados nas situações concretas e nas experiências pessoais. Seu processo de desenvolvimento de conceitos não inclui pois, a atitude mediada e a atividade meta cognitiva típicas de uma exposição sistemática ao conhecimento estruturado. Para o professor, o processo seria o de refazer determinados conceitos espontâneos em relação à sua prática docente para articular novos conceitos científicos que pudessem ajudá-lo em seu fazer.

Os conceitos científicos, diferentemente dos espontâneos, estão organizados em sistemas consistentes de inter- relações. Por sua inclusão num sistema e por implicar numa relação mediada, desde o início de sua aquisição, eles envolvem uma atitude de consciência por parte do sujeito que domina seus conteúdos, no nível de definição e de relação com outros conceitos.

A aprendizagem é pois, fundamental porque desperta processos internos ao desenvolvimento que só podem ocorrer quando o sujeito interage com outros membros do grupo. "A aprendizagem e o desenvolvimento são o centro da análise das origens e da formação dos conceitos científicos” (VIGOTSKI, 2001, p. 365).

Vigotski define que o desenvolvimento não decorre apenas de um esforço individual do sujeito, mas encontra-se condicionado às trocas interpessoais, sendo a linguagem fruto desta interação e instrumento que possibilita, a partir de um processo de internalização, o desenvolvimento da atividade interna. Desta forma, o desenvolvimento da 
linguagem e a capacidade de simbolizar dependem da existência de outros sujeitos, interlocutores nesse processo. A interlocução oportuniza transformações nos interlocutores envolvidos, considerando-se assim, que tanto os alunos como o professor vivenciam, dinamicamente, um processo de reelaboração interna.

O professor não é aquele que ensina, mas também o que aprende, um interlocutor, ativo, que busca a apropriação de conhecimentos, através da apropriação e ressignificação dos conceitos. A função da aprendizagem sistemática para a escola vigotskiana, pode ser considerada o desenvolvimento dos conceitos que se transformam de espontâneos em científicos. O processo de aprendizagem ocorrido na escola (ou em outra instância educativa) deveria propiciar, então aos alunos e aos professores o acesso à cultura letrada, ao conhecimento acumulado, construindo o próprio modo de articulação dos conceitos. A aprendizagem, nessa perspectiva, é a fonte de desenvolvimento desses conceitos científicos, interferindo decisivamente no curso do desenvolvimento, cabendo- lhe, de certo modo, organizar o processo, determinar o seu destino. "a aprendizagem adequadamente organizada resulta em desenvolvimento mental e põe em movimento vários processos de desenvolvimento que, de outra forma, seriam impossíveis de acontecer”. (VIGOTSKI, 1988, p. 101).

Com relação à aprendizagem do professor (e do aluno) que interessa para este estudo, pode-se dizer que quando o processo se volta para níveis já atingidos, ela torna-se ineficaz por não exigir um avanço no processo de desenvolvimento. Talvez essa questão explique um pouco da preocupação que se tem em não atingir objetivos propostos para à educação institucionalizada.

A aprendizagem de diferentes conteúdos interagem entre si, contribuindo para o desenvolvimento das funções psicológicas. Esse fato ocorre porque o processo de apreender os conteúdos, os próprios conteúdos e as principais funções psicológicas envolvidas em seu estudo são interdependentes. Assim, cada aprendizagem facilita a aprendizagem de outra e as funções psicológicas estimuladas por elas avançam num longo e complicado processo.

Um elemento importante para a compreensão do desenvolvimento dos conceitos e que deve ser retomada, é a questão da "mediação". Mediação é o processo de intervenção de um elemento intermediário numa relação. Nesse sentido, a relação do professor com o conhecimento passa a ser mediada por um terceiro elemento. A mediação é um processo essencial para tornar possível atividades psicológicas voluntárias, intencionais, controladas pelo próprio sujeito. É um conceito central para entender o fundamento histórico do funcionamento psicológico e remete ao pressuposto vigotskiano que a relação homemmundo é uma relação mediada, sendo os sistemas simbólicos os elementos intermediários nessa relação. Portanto, a inserção do indivíduo num determinado ambiente cultural é parte de sua própria constituição como pessoa.

É importante pensar o professor no grupo cultural que lhe fornece os instrumentos e signos que possibilitarão o desenvolvimento de suas atividades psicológicas mediadas. $\mathrm{O}$ seu desenvolvimento então, está baseado no aprendizado que sempre envolve a interferência, direta ou indireta de outros indivíduos e a reconstrução pessoal da experiência e dos significados .O processo de desenvolvimento do sujeito é marcado por sua inserção em um determinado grupo cultural e dá-se de fora para dentro. As atividades externas que a pessoa realiza serão interpretadas pelas outras, de acordo com os significados culturalmente 
estabelecidos. Só então os significados serão internalizados e compreendidos pela própria pessoa e pelo grupo ao seu redor.

\section{Concluindo}

A constituição do sujeito realiza-se através da relação dialética apropriação/ objetivação, no contexto de sua cultura, mas essa constituição não pode ser considerada sempre com vistas à hominização, e vai depender das condições objetivas de vida e de trabalho, em sociedade. Nesse sentido, será alienador todo processo que não resultar na apropriação dos bens da cultura e no sujeito humanizado. Para a abordagem históricocultural portanto, é importante que o homem tenha sua atividade que deve ser objetivadora, social e consciente.

A única maneira de estudar as formas superiores de pensamento, através da atividade é concentrando-se no processo e não no produto. Para isso, é importante alterar o caráter automático, mecanizado e fossilizado das formas de pensamento do professor.

Nessa perspectiva, de acordo com Vigotski (1988), o resultado será uma forma qualitativamente nova de pensamento. O rompimento com alguns conceitos e reconstrução de outros consiste, então num processo dialético complexo caracterizado pela periodicidade, desigualdade nas diferentes funções, metamorfose ou transformação qualitativa de uma forma em outra. Sem desprezar o resultado, deverá ser privilegiado o estudo do processo por meio do qual se desenvolve o psiquismo humano.

A consciência do professor (sujeito da aprendizagem) é um produto histórico porque aparece nas relações sujeito/mundo sendo mediatizada pelo trabalho docente. Portanto, torna-se muito importante para ele, essa atividade em seu processo de constituição e as condições em que ela se desenvolve.

Vigotski trabalha sempre com a idéia de reelaboração, pelo sujeito, dos significados que lhe são transmitidos pelo grupo social, e assim a consciência individual é um elemento muito importante no desenvolvimento das funções psicológicas superiores. $\mathrm{O}$ processo constante da recriação da cultura, é a base do processo histórico, nas sociedades humanas, em constante transformação.

Nesse caso, os conceitos científicos vão gradualmente transformando os espontâneos, organizando-os num sistema que leva a um nível maior de desenvolvimento. As generalizações vão provocando mudanças nas operações intelectuais. O sujeito passa a perceber que o signo não é fixo, nem imutável e que adquire vários sentidos em momentos e espaços diferenciados. O sujeito-professor é capaz de criar e recriar a aprendizagem e não reproduz mais meramente um significado que lhe foi transmitido, passa a ser capaz de fazer uma síntese, elaborar o seu próprio pensar e pensar sobre sua atividade.

Importante viver experiências enriquecedoras, pelo menos nos espaços em que houver possibilidade, lembrando Leontiev (1978b), quando afirma que o fato do agir humano ser conscientemente dirigido por fins, possibilita tanto o desenvolvimento humanizador da atividade e da consciência, quanto a separação entre o significado e o sentido da ação. Nesse sentido, embora vivendo situações objetivas que fogem a seu controle modificar, o professor poderá vir a se tornar o sujeito- protagonista da atividade docente. 
Notas

${ }^{1}$ ) Neste artigo, a expressão “escola de Vigotski”, engloba, tanto as idéias desse autor, como as de seus companheiros de trabalho, principalmente, Leontiev. Lúria e Rubstein.

2) Foram utilizadas as explicações dadas por Leontiev, a respeito das categorias atividade e consciência na compreensão do psiquismo humano, mas preferiu-se o uso da categoria identidade, utilizada por uma linha da Psicologia Social, especificamente representada por Ciampa (1994), ao tratar das questões sujeito/ objeto e no entendimento de um homem contextualizado que está sempre se transformando.

3) Autores que realizaram estudos na perspectiva da Educação/Psicologia, dando ênfase à crítica aos reducionismos impostos nessa relação.

4)Trabalho realizado com os acadêmicos da UFMS que queriam aumentar os seus conhecimentos sobre a teoria de Vigotski. Muitas das considerações deste artigo sobre a aprendizagem do professor são originadas dessa experiência, que permitiu uma observação sobre a maneira como os professores aprendem, ao mesmo tempo em que realizam a sua atividade de ensinar.

5)Vigotski estabelece um percurso, através do qual a criança ou o adulto podem transformar conceitos espontâneos em científicos, observando que a formação de conceitos é um meio específico e original de pensamento, o fator imediato que determina o desenvolvimento desse novo modo de pensar qualitativamente original e irredutível a outras operações intelectuais elementares.

6) Utiliza-se o termo "aprendizado”, em Vigotski, justamente para marcar a ênfase nos processos históricoculturais, que inclui a interdependencia dos sujeitos envolvidos no processo. O termo utilizado em russo, segundo Marta Kohl (1998), é “obuchenie”, que significa processo de ensino e de aprendizagem, mas, quando se usa aprendizado, é para enfatizar um significado mais abrangente, por envolver as relações sociais.

\section{REFERÊNCIAS:}

ALVITE, Maria Mercedes Capelo. Didática e Psicologia: crítica ao psicologismo na Educação. São Paulo: Loyola, 1981.

CIAMPA, A C. A estória do Severino e a história da Severina: Um ensaio de psicologia Social. São Paulo: Brasiliense, 1994.

DUARTE, N. Vigotski e o "aprender a aprender"- crítica às apropriações neoliberais e pós- modernas da teoria vigotskiana. $2^{\mathrm{a}}$ ed. São Paulo: Autores Associados, 2001.

FERREIRA, N.T. O Homem e as redes de informações. Rio de Janeiro: URFJ, 1996.

FORQUIN, J.C. Escola e Cultura. As bases sociais e epistemológicas do conhecimento escolar. Porto Alegre: Artes Médicas, 1993.

IMBERNÓN, F. (Coord.). A Educação no Século XXI- os desafios do futuro imediato. Porto Alegre: Artmed, 2000.

LEONTIEV, A .N. Actividad, Consciencia y Personalidad. Buenos Aires: Ciencias del Hombre, 1978 (a).

LEONTIEV, A .N. O Desenvolvimento do Psiquismo. Lisboa: Livros Horizonte, 1978 (b). 
PETITAT, A. Produção da Escola- Produção da Sociedade. Análise sócio- histórica de alguns momentos decisivos da evolução escolar no ocidente. Trad. Eunice Gruman. Porto Alegre: Artes Médicas, 1994.

REY, G. F. Sujeito e Subjetividade. São Paulo: Pioneira, 2003.

SACRISTÁN, G. Consciência e ação sobre a prática como libertação profissional dos professores. IN: NÓVOA, A. ( Coord.). Profissão Professor. Lisboa: Porto editora, 1991.

VYGOTSKY, LURIA E LEONTIEV. Linguagem, desenvolvimento e aprendizagem. São Paulo, Ïcone/Edusp, 1988.

VIGOTSKI,L. S. A Construção do pensamento e da Linguagem. São Paulo: Martins Fontes, 2001.

VIGOTSKI, L. S. A formação social da mente. 6 ed. São Paulo: Martins Fontes, 2003. 